\title{
Effect of Prior Exercise on the Partitioning of an Intestinal Glucose Load between Splanchnic Bed and Skeletal Muscle
}

\author{
Katherine S. Hamilton, Fiona K. Gibbons, Deanna P. Bracy, D. Brooks Lacy, Alan D. Cherrington, and David H. Wasserman
}

Department of Molecular Physiology and Biophysics, Vanderbilt University School of Medicine, Nashville, Tennessee 37232

\begin{abstract}
Exercise leads to marked increases in muscle insulin sensitivity and glucose effectiveness. Oral glucose tolerance immediately after exercise is generally not improved. The hypothesis tested by these experiments is that after exercise the increased muscle glucose uptake during an intestinal glucose load is counterbalanced by an increase in the efficiency with which glucose enters the circulation and that this occurs due to an increase in intestinal glucose absorption or decrease in hepatic glucose disposal. For this purpose, sampling (artery and portal, hepatic, and femoral veins) and infusion (vena cava, duodenum) catheters and Doppler flow probes (portal vein, hepatic artery, external iliac artery) were implanted $17 \mathrm{~d}$ before study. Overnightfasted dogs were studied after $150 \mathrm{~min}$ of moderate treadmill exercise or an equal duration rest period. Glucose $\left(\left[{ }^{14} \mathrm{C}\right]\right.$ glucose labeled) was infused in the duodenum at $8 \mathrm{mg} /$ $\mathrm{kg} \cdot \mathrm{min}$ for $150 \mathrm{~min}$ beginning $30 \mathrm{~min}$ after exercise or rest periods. Values, depending on the specific variable, are the mean $\pm S E$ for six to eight dogs. Measurements are from the last $60 \mathrm{~min}$ of the intraduodenal glucose infusion. In response to intraduodenal glucose, arterial plasma glucose rose more in exercised $(103 \pm 4$ to $154 \pm 6 \mathrm{mg} / \mathrm{dl})$ compared with rested $(104 \pm 2$ to $139 \pm 3 \mathrm{mg} / \mathrm{dl})$ dogs. The greater increase in glucose occurred even though net limb glucose uptake was elevated after exercise ( $35 \pm 5 \mathrm{vs} .20 \pm 2 \mathrm{mg} / \mathrm{min})$ as net splanchnic glucose output $(5.1 \pm 0.8 \mathrm{vs} .2 .1 \pm 0.6 \mathrm{mg} / \mathrm{kg}$ min) and systemic appearance of intraduodenal glucose $(8.1 \pm 0.6 \mathrm{vs}$. $6.3 \pm 0.7 \mathrm{mg} / \mathrm{kg} \cdot \mathrm{min})$ were also increased due to a higher net gut glucose output $(6.1 \pm 0.7 \mathrm{vs} .3 .6 \pm 0.9 \mathrm{mg} /$ $\mathrm{kg} \cdot \mathrm{min})$. Adaptations at the muscle led to increased net glycogen deposition after exercise $[1.4 \pm 0.3$ vs. $0.5 \pm 0.1 \mathrm{mg} /$ (gram of tissue $\cdot 150 \mathrm{~min}$ )], while no such increase in glycogen storage was seen in liver [3.9 $\pm 1.0 \mathrm{vs.} 4.1 \pm 1.1 \mathrm{mg} /$ (gram of tissue $\cdot 150 \mathrm{~min}$ ) in exercised and sedentary animals, respectively]. These experiments show that the increase in the ability of previously working muscle to store glycogen is not solely a result of changes at the muscle itself, but is also a result of changes in the splanchnic bed that increase the effi-
\end{abstract}

Address correspondence to David H. Wasserman, Ph.D., Light Hall Rm. 702, Department of Molecular Physiology and Biophysics, Vanderbilt University School of Medicine, Nashville, TN 37232. Phone: 615-343-7335; FAX: 615-322-7236; E-mail: david.wasserman@mcmail.vanderbilt.edu

Received for publication 10 January 1996 and accepted in revised form 10 April 1996.

J. Clin. Invest.

(C) The American Society for Clinical Investigation, Inc.

0021-9738/96/07/125/11 \$2.00

Volume 98, Number 1, July 1996, 125-135 ciency with which oral glucose is made available in the systemic circulation. (J. Clin. Invest. 1996. 98:125-135.) Key words: exertion • gut • liver • skeletal muscle • glucose • carbohydrate

\section{Introduction}

Despite the adaptations that facilitate muscle glucose disposal after acute exercise, the increase in systemic blood glucose that occurs in response to oral glucose is generally no less (1-3) and may even be greater than the response in sedentary subjects $(4,5)$. This suggests that prior exercise leads to extramuscular adaptations that increase glucose availability to peripheral tissues during an oral glucose load. Since the rate of glucose entry into the systemic circulation after feeding is determined by gastrointestinal glucose absorption and net hepatic glucose balance, it is likely that one or both of these processes are influenced by prior exercise. Despite the integral role of splanchnic tissues in glucoregulation, very little is known about how these tissues function after the added metabolic demands placed upon them by physical exercise.

After exercise, liver and muscle glycogen stores are depleted and gluconeogenic efficiency and lipolysis are elevated (6). Furthermore, basal $(1,6,7)$ and glucose-stimulated $(2,4,5,8)$ insulin levels are often reduced. Adaptations after exercise compensate for reduced circulating insulin at the muscle (9). However, it is unclear whether hepatic sensitivity to insulin or any other determinant of hepatic glucose metabolism is increased in a similar manner. It was the aim of these studies to determine whether the gut and liver adapt after exercise to facilitate the disposition of oral glucose. Specifically, the work herein describes the influence of prior exercise and intraduodenal glucose on (a) intestinal glucose absorption; (b) net hepatic glucose uptake and its determinants (e.g., hepatic glucose load, insulin, arterial-portal vein glucose gradient); (c) partitioning of glucose between oxidative and nonoxidative processes within the liver and skeletal muscle; and (d) partitioning of carbons between splanchnic bed and previously working limb. These aims were assessed using dual isotopic methods in a chronically catheterized conscious dog model.

\section{Methods}

Animal maintenance and surgical procedures. Mongrel dogs $(n=15$; mean wt $20.8 \pm 0.4 \mathrm{~kg}$ ) of either gender that had been fed a standard diet (beef dinner from Kal Kan, Vernon, CA and Wayne Lab Blox: $51 \%$ carbohydrate, $31 \%$ protein, $11 \%$ fat, and $7 \%$ fiber based on dry weight, Allied Mills, Inc., Chicago, IL) were studied. The dogs were housed in a facility that met American Association for the Accreditation of Laboratory Animal Care guidelines and the protocols were approved by the Vanderbilt University School of Medicine Animal Care Committee. At least $16 \mathrm{~d}$ before each experiment a laparotomy was performed under general anesthesia (sodium pentobarbital, 25 $\mathrm{mg} / \mathrm{kg}$ ). Silastic catheters (0.03 ID) were inserted into the vena cava 
for tracer and indocyanine green infusions. A silastic catheter $(0.08$ ID) was inserted through the duodenal mucosa $3-4 \mathrm{~cm}$ below the pylorus for infusion of glucose (cold and U-[ $\left.{ }^{14} \mathrm{C}\right]$ glucose) and secured with a purse string stitch. Silastic catheters $(0.04$ ID) were inserted into the portal vein and left common hepatic vein for blood sampling. Incisions were also made in the neck region and inguinal region for the placement of arterial and common iliac vein sampling catheters, respectively. The carotid artery was isolated and a silastic catheter (0.04 ID) was inserted so that its tip rested in the aortic arch. A silastic catheter ( 0.03 ID) was introduced into the common iliac vein via a lateral circumflex vein. Exposure of the lateral circumflex vein was achieved with a $2-\mathrm{cm}$ incision in the lower femoral region and dissection of the vein from the subcutaneous tissues. The catheter tip was positioned in the common iliac vein, distal to the anastomosis with the vena cava. The median sacral vein was ligated to prevent dilution from other sites. Verification of catheter placement was made through the abdominal incision site. After insertion, the catheters were filled with saline containing heparin $(200 \mathrm{U} / \mathrm{ml}$; Abbott Laboratories, North Chicago, IL) and their free ends were knotted.

Doppler flow probes (Instrumentation Development Laboratory, Baylor University School of Medicine, Waco, TX) were used to measure portal vein, hepatic artery, and external iliac artery blood flows (10). Briefly, a small section of the portal vein, upstream from its junction with the gastroduodenal vein, was cleared of tissue, and a 7.0-mm ID flow cuff was placed around the vessel and secured. The gastroduodenal vein was isolated and then ligated proximal to its coalescence with the portal vein. A section of the main hepatic artery lying proximal to the portal vein was isolated and a 3.0-mm ID flow cuff was placed around the vessel and secured. The external iliac artery was accessed from the abdominal incision, dissected free of surrounding tissue, and fitted with a 6.0-mm ID flow probe cuff which was then secured around the vessel. The Doppler probe leads and the knotted free catheter ends, with the exception of the carotid artery and common iliac vein catheters, were stored in a subcutaneous pocket in the abdominal region so that complete closure of the skin incision was possible. The carotid artery and the common iliac vein catheters were stored under the skin of the neck and inguinal regions, respectively.

Starting $1 \mathrm{wk}$ after surgery, dogs were exercised on a motorized treadmill, regardless of whether they were used for sedentary or exercise experiments, so that they would be familiar with treadmill running. Animals were not exercised during the $48 \mathrm{~h}$ preceding an experiment. Only animals that had ( $a$ ) a leukocyte count $<18,000 / \mathrm{mm}^{3},(b)$ a hematocrit $>36 \%,(c)$ normal stools, and $(d)$ a good appetite (consuming all of the daily ration) were used.

Studies were conducted after an 18-h fast, since this allows for complete meal absorption in the $\operatorname{dog}(11)$. On the day of the experiment, the subcutaneous ends of the catheters were freed through small skin incisions made under local anesthesia (2\% lidocaine; Astra Pharmaceutical Products, Worcester, MA) in the abdominal and neck regions. The contents of each catheter were aspirated and they were flushed with saline. Silastic tubing was connected to the exposed catheters and brought to the back of the dog where they were secured with quick drying glue. Saline was infused in the arterial catheter throughout experiments $(0.1 \mathrm{ml} / \mathrm{min})$.

Experimental procedures. Animals were either exercised at a moderate intensity $(100 \mathrm{~m} / \mathrm{min}, 12 \%$ grade $)$ on a motorized treadmill $(n=7)$ or remained sedentary $(n=8)$ for a corresponding time pe$\operatorname{riod}(\mathrm{t}=-180$ to $-30 \mathrm{~min})$. The exercise intensity and duration used in these experiments has been shown previously to result in a twofold increase in heart rate (12) and an increase in $\mathrm{O}_{2}$ uptake to $50 \%$ of maximum (13). Furthermore, a fall in liver glycogen from $35 \pm 4$ to $13 \pm 3$ grams results (6). A period of exercise recovery or continued rest followed ( $\mathrm{t}=-30$ to $150 \mathrm{~min})$. Glucose (50\% dextrose), mixed with $\mathrm{U}-\left[{ }^{14} \mathrm{C}\right]$ glucose to give a specific activity of $\sim 8,700 \mathrm{dpm} / \mathrm{mg}$, was given as a primed infusion $(150 \mathrm{mg} / \mathrm{kg} ; 8 \mathrm{mg} / \mathrm{kg} \cdot \mathrm{min})$ into the duodenum from $\mathrm{t}=0$ to $150 \mathrm{~min}$. At $\mathrm{t}=-70 \mathrm{~min}$ primers of $3-\left[{ }^{3} \mathrm{H}\right]$ glucose $(42 \mu \mathrm{Ci})$ and sodium ${ }^{14} \mathrm{C}$-bicarbonate $(0.64 \mu \mathrm{Ci} / \mathrm{kg})$ were given. Constant rate venous infusions of $3-\left[{ }^{3} \mathrm{H}\right]$ glucose $(0.30 \mu \mathrm{Ci} / \mathrm{min})$ and in- docyanine green $\left(0.1 \mathrm{mg} / \mathrm{m}^{2} \cdot \min \right)$ were also initiated at this time. These infusions were continued for the duration of the study. Isotopes were obtained from New England Nuclear (Boston, MA) and indocyanine green was purchased from Hynson, Westcott, and Dunning (Baltimore, MD). Arterial samples were drawn at 5-min intervals from $\mathrm{t}=-20$ to $0 \mathrm{~min}$ and at 15 -min intervals from 0 to $150 \mathrm{~min}$. Portal, hepatic, and common iliac vein samples were drawn at $\mathrm{t}=-20$, $-10,0,15,30,60,90,120$, and $150 \mathrm{~min}$. Portal or hepatic vein catheter failure occurred in three experiments and consequently trans-hepatic sampling could not be performed. Portal vein, hepatic artery, and external iliac artery blood flows were recorded continuously from the frequency shifts of the pulsed sound signal emitted from the Doppler flow probes (10). At the cessation of the experiment animals were anesthetized using sodium pentobarbital, an abdominal midline incision was made, and $\sim 2$-gram biopsies were taken from each of the seven lobes of the liver. An incision was then made on the medial aspect of the left hindlimb and $\sim 2$-gram biopsies were taken from three hindlimb skeletal muscles (gastrocnemius, gracilis, vastus lateralis). Upon excising, all tissue samples were immediately freeze clamped in liquid nitrogen. The time interval between the induction of anesthesia and last biopsy was $<5 \mathrm{~min}$.

Processing of blood and tissue samples. After centrifugation plasma and deproteinized blood were stored on dry ice until the completion of the experiment. Samples were then stored at $-70^{\circ} \mathrm{C}$ until later analysis. Plasma glucose levels were determined by the glucose oxidase method using a glucose analyzer (Beckman Instruments, Fullerton, CA). For the determination of plasma glucose radioactivity $\left({ }^{3} \mathrm{H}\right.$ and ${ }^{14} \mathrm{C}$ ), samples were deproteinized with barium hydroxide (Sigma Immunochemicals, St. Louis, MO) and zinc sulfate (Sigma Immunochemicals), placed over Dowex 50W-X8 (Bio Rad Laboratories, Richmond, CA) and Amberlite (Rohm and Haas, Philadelphia, PA) resins, the supernatant was evaporated, and reconstituted in $1 \mathrm{ml}$ of water and $10 \mathrm{ml}$ of Ecolite ${ }^{+}$(ICN Biomedicals, Irvine, CA). Radioactivity was then determined by dual-label liquid scintillation counting using a Beckman LS 5000TD. Whole blood lactate, glycerol, and glucose concentrations were determined in samples deproteinized with an equal volume of $8 \%$ perchloric acid by enzymatic methods (14) on an AutoAnalyzer (Technicon, Tarrytown, NY) or on a Monarch 2000 centrifugal analyzer (Instrumentation Laboratories, Lexington, MA). Enzymes used in analyses of metabolites and amino acids were obtained from Sigma Immunochemicals or Boehringer-Mannheim Biochemicals (Mannheim, Germany). Whole blood lactate and glucose radioactivities were measured on the deproteinized whole blood supernatant by an established method (15). The ${ }^{14} \mathrm{CO}_{2}$ in whole blood was liberated by acidification with hydrochloric acid and trapped on chromatography paper using hyamine hydroxide.

Liver and muscle glycogen mass and radioactivity were measured by a previously described method (16). Glycogen synthase activity was determined in the absence of glucose 6-phosphate and in the presence of $10 \mathrm{mM}$ glucose 6-phosphate by the method of Golden et al. (17). Glucose phosphorylating activity in liver (glucokinase) and skeletal muscle (hexokinase) homogenates was measured by a previously described method (18).

Immunoreactive insulin was measured using a double antibody system (interassay coefficient of variation $[\mathrm{CV}]^{1}$ of $10 \%$ ) (19). Immunoreactive glucagon $(3,500 \mathrm{~mol} \mathrm{wt})$ was measured in plasma samples containing $50 \mu \mathrm{l}$ of $500 \mathrm{KIU} / \mathrm{ml}$ Trasylol (FBA Pharmaceuticals, New York) using a double antibody system (interassay CV of 7\%) modified from the method developed by Morgan and Lazarow for insulin (19). Glucagon and insulin antisera were obtained from Dr. R.L. Gingerich (Washington University School of Medicine, St. Louis, MO),

1. Abbreviations used in this paper: $\mathrm{CV}$, coefficient of variation; $\mathrm{HAF}$, hepatic artery blood flow; NEFA, nonesterified fatty acid; PVF, portal vein blood flow; $R_{\mathrm{a}}$, glucose appearance; $R_{\mathrm{d}}$, glucose disappearance; SA, specific activity. 
and the standard glucagon and ${ }^{125}$ I-glucagon were obtained from Novo Research Institute (Copenhagen, Denmark). Standard insulin and ${ }^{125}$ I-insulin were obtained from Linco Research Inc. (St. Louis, MO). Plasma norepinephrine and epinephrine levels were determined using an HPLC technique (interassay $\mathrm{CV}$ of 11 and $13 \%$, respectively) (20). Plasma cortisol was measured using the Clinical Assays Gamma Coat ${ }^{\mathrm{TM}}$ Radioimmunoassay Kit (Clinical Assays, Travenol-Genetech Diagnostics, Cambridge, MA) (interassay CV of $6 \%$ ).

Calculations. Total glucose appearance $\left(R_{\mathrm{a}}\right)$ and disappearance $\left(R_{\mathrm{d}}\right)$ were determined by non-steady state equations for isotope (3- $\left[{ }^{3} \mathrm{H}\right]$ glucose) dilution (21) using a pool fraction of 0.65 (22). Hepatic $\left[{ }^{14} \mathrm{C}\right]$ glucose production was determined in a manner analogous to the measurement of $R_{\mathrm{a}}$, with the difference being that the specific activity (SA) was the ratio of $\left[{ }^{3} \mathrm{H}\right]$ glucose to $\left[{ }^{14} \mathrm{C}\right]$ glucose instead of the ratio of $\left[{ }^{3} \mathrm{H}\right]$ glucose to glucose. The systemic rate of appearance of the intraduodenal glucose load was calculated by dividing the hepatic $\left[{ }^{14} \mathrm{C}\right]$ glucose production by the intraduodenal infusate SA. Endogenous $R_{\mathrm{a}}$ was calculated as the total $R_{\mathrm{a}}$ minus the systemic rate of appearance of the intraduodenal glucose load. The systemic appearance of intraduodenal glucose will be overestimated by an amount that is dependent on the rate that $\left[{ }^{14} \mathrm{C}\right]$ glucose is recycled. As a consequence, endogenous $R_{\mathrm{a}}$ will be underestimated by the same magnitude.

Net hepatic lactate, glucose, and ${ }^{14} \mathrm{CO}_{2}$ balances were determined by the formula $\mathrm{HAF} \times([\mathrm{H}]-[\mathrm{A}])+\mathrm{PVF} \times([\mathrm{H}]-[\mathrm{P}])$, where $[\mathrm{A}]$, $[\mathrm{P}]$, and $[\mathrm{H}]$ are the arterial, portal vein, and hepatic vein substrate concentrations and HAF and PVF are the hepatic artery and portal vein blood flows. These calculations were performed using Dopplerdetermined blood flow measurements except in one experiment in which probe failure required the use of results obtained using the dye extraction method. The dye extraction technique measures total hepatic blood flow but does not differentiate between inputs from the portal vein and hepatic artery. In the experiment that was reliant on the dye extraction technique, portal vein blood flow was assumed to be $80 \%$ of total hepatic blood flow (23). The load of glucose reaching the liver equals $[\mathrm{P}] \times \mathrm{PVF}+[\mathrm{A}] \times \mathrm{HAF}$. Net gut balances were calculated as PVF $\times([\mathrm{P}]-[\mathrm{A}])$ and net splanchnic glucose balances were calculated as $(\mathrm{HAF}+\mathrm{PVF}) \times([\mathrm{H}]-[\mathrm{A}])$.

Net limb balances were calculated as LF $\times([\mathrm{A}]-[\mathrm{I}])$. LF is limb blood (or plasma) flow through the external iliac artery and [I] is the substrate level in the common iliac vein. The sign was reversed for the calculation of limb ${ }^{14} \mathrm{CO}_{2}$ production. Limb fractional glucose extraction was calculated as the net limb glucose uptake divided by the limb glucose load, which was considered equal to LF $\times[\mathrm{A}]$. Blood levels and flows were used for the calculation of all hepatic and limb balances. The ratio of blood to plasma glucose was calculated for the basal period and the glucose infusion period for each dog at each of

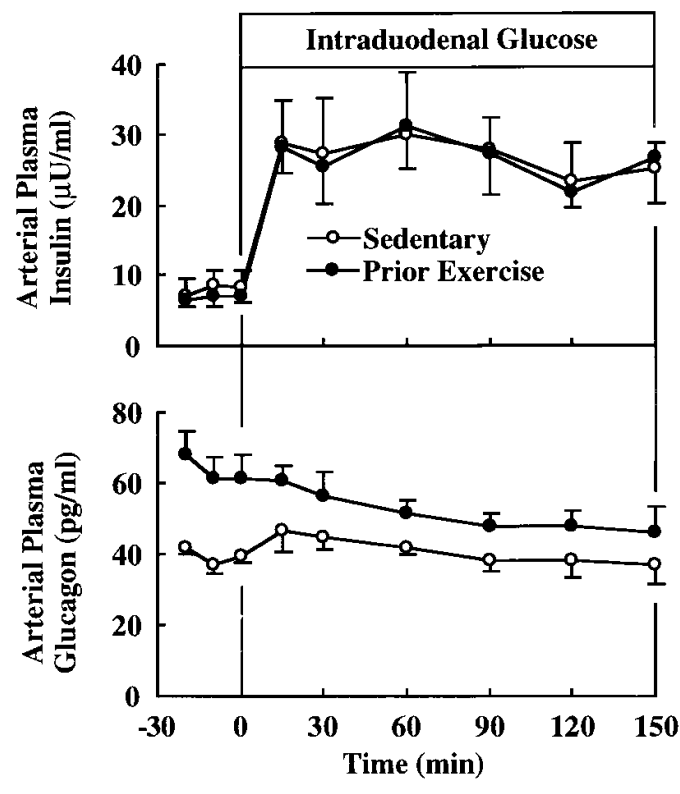

Figure 1. Arterial plasma insulin (top) and glucagon (bottom) during an intraduodenal glucose load $(8 \mathrm{mg} / \mathrm{kg} \cdot \mathrm{min})$ in sedentary (open circles) and exercised (closed circles) dogs. Data are mean \pm SE; $n=8$ and 7 sedentary and exercised dogs, respectively. Plasma glucagon levels were significantly elevated after exercise from -20 to $30 \min (P<0.05-0.001)$.

the four sampling sites. Plasma glucose values were then multiplied by their corresponding ratio (i.e., blood glucose/plasma glucose) to convert to blood glucose concentrations. The advantage of using plasma glucose measurements is that a large number of replicates can be done quickly and at little added cost. The ability to measure replicate samples reduces the measurement $\mathrm{CV}$. The conversion to blood values alleviates the need for assumptions regarding the equilibration of substrates between red cell and plasma water.

Hepatic conversion of glucose to $\mathrm{CO}_{2}$ was calculated as the net hepatic ${ }^{14} \mathrm{CO}_{2}$ production rate divided by the hepatic $\left[{ }^{14} \mathrm{C}\right]$ glucose precursor SA. The precursor SA was considered to be the $\left[{ }^{14} \mathrm{C}\right]$ glucose SA in the inflowing blood to the liver and was calculated as (\{portal vein $\left[{ }^{14} \mathrm{C}\right]$ glucose SA $\} \times \mathrm{PVF}+\left\{\right.$ artery $\left[{ }^{14} \mathrm{C}\right]$ glucose $\left.\mathrm{SA}\right\} \times$ $\mathrm{HAF}) /(\mathrm{HAF}+\mathrm{PVF})$. Since, during a $\left[{ }^{14} \mathrm{C}\right]$ glucose infusion $\left[{ }^{14} \mathrm{C}\right]$ lac-

Table I. Arterial Plasma Concentrations of Cortisol, Norepinephrine, and Epinephrine in Sedentary and Exercised Dogs before and during Intraduodenal Glucose

\begin{tabular}{|c|c|c|c|c|c|c|c|}
\hline & \multirow[b]{2}{*}{ Pre-glucose load } & \multicolumn{6}{|c|}{ Intraduodenal glucose } \\
\hline & & $15 \mathrm{~min}$ & $30 \mathrm{~min}$ & $60 \mathrm{~min}$ & $90 \mathrm{~min}$ & $120 \mathrm{~min}$ & $150 \mathrm{~min}$ \\
\hline \multicolumn{8}{|c|}{ Arterial plasma cortisol $(\mu \mathrm{g} / \mathrm{dl})$} \\
\hline Sedentary & $2.0 \pm 0.4$ & $3.7 \pm 0.9$ & $4.4 \pm 1.2$ & $5.1 \pm 1.3$ & $3.8 \pm 0.7$ & $4.8 \pm 1.4$ & $4.2 \pm 1.5$ \\
\hline Prior exercise & $3.7 \pm 0.6^{*}$ & $6.8 \pm 1.7$ & $7.7 \pm 1.9$ & $7.0 \pm 2.7$ & $5.0 \pm 1.7$ & $5.3 \pm 1.4$ & $3.6 \pm 1.6$ \\
\hline \multicolumn{8}{|c|}{ Arterial plasma norepinephrine (pg/ml) } \\
\hline Sedentary & $128 \pm 21$ & $130 \pm 20$ & $132 \pm 26$ & $128 \pm 18$ & $124 \pm 13$ & $110 \pm 12$ & $117 \pm 12$ \\
\hline Prior exercise & $187 \pm 44$ & $152 \pm 26$ & $159 \pm 19$ & $159 \pm 24$ & $137 \pm 24$ & $165 \pm 45$ & $158 \pm 32$ \\
\hline \multicolumn{8}{|c|}{ Arterial plasma epinephrine $(\mathrm{pg} / \mathrm{ml})$} \\
\hline Sedentary & $83 \pm 10$ & $96 \pm 30$ & $128 \pm 34$ & $110 \pm 24$ & $92 \pm 21$ & $87 \pm 15$ & $94 \pm 28$ \\
\hline Prior exercise & $137 \pm 23^{*}$ & $133 \pm 38$ & $115 \pm 32$ & $102 \pm 21$ & $80 \pm 26$ & $93 \pm 24$ & $124 \pm 37$ \\
\hline
\end{tabular}

Data are mean \pm SE. $n=8$ and 7 in sedentary and exercised animals, respectively. *Values are significantly different compared with sedentary animals $(P<0.05-0.002)$. 


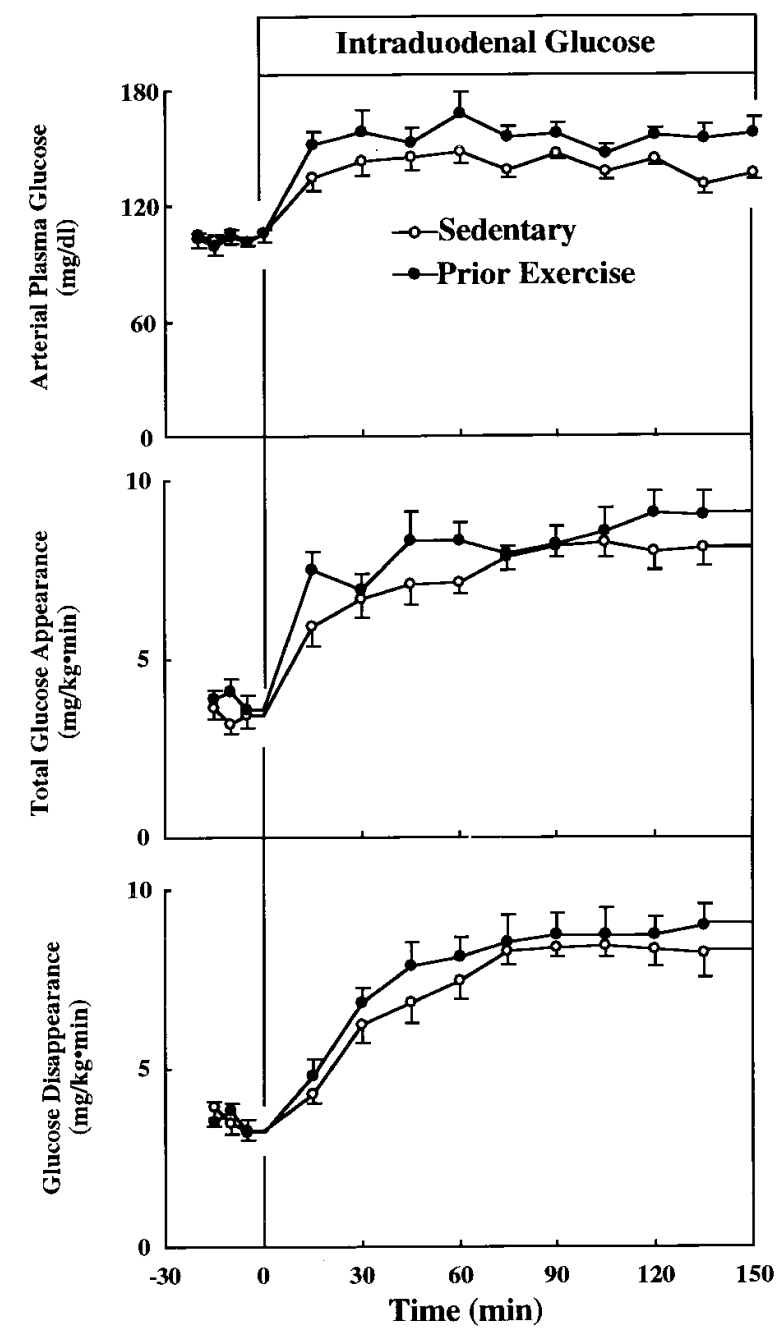

Figure 2. Arterial plasma glucose (top), total glucose appearance (middle), and glucose disappearance (bottom) during an intraduodenal glucose load $(8 \mathrm{mg} / \mathrm{kg} \cdot \mathrm{min})$ in sedentary (open circles) and exercised (closed circles) dogs. Data are mean \pm SE; $n=8$ and 7 sedentary and exercised dogs, respectively, for arterial plasma glucose and $n=$ 8 and 6 sedentary and exercised dogs, respectively, for total glucose appearance and disappearance. Arterial plasma glucose was significantly higher in exercised dogs at $\mathrm{t}=15,30,60,75,120$, and $135 \mathrm{~min}$ $(P<0.02-0.001)$. Total glucose appearance was significantly higher in exercised dogs at $\mathrm{t}=15$ and $45 \min (P<0.05-0.01)$.

tate accumulates, it is necessary to consider lactate SA in the calculation of precursor SA when $\left[{ }^{14} \mathrm{C}\right]$ lactate uptake is present. In these experiments, lactate was predominantly produced by the liver and, therefore, was not included in the calculation of hepatic glucose metabolism. Net limb lactate uptake was present during the intraduodenal glucose infusion requiring that lactate $\mathrm{SA}$ be considered in the precursor SA for limb glucose conversion to $\mathrm{CO}_{2}$. Limb glucose + lactate oxidation was calculated as the $\operatorname{limb}{ }^{14} \mathrm{CO}_{2}$ output divided by the sum of the SAs of glucose and lactate weighted for their respective net limb uptakes. Limb nonoxidative glucose + lactate metabolism was determined as the difference between net limb glucose + lactate uptake and oxidation. Inclusion of lactate SA into these calculations resulted in a $<5 \%$ change when compared with values obtained when lactate was not considered. Assumptions involved in these calculations have been described in detail previously $(24,25)$.

Net glycogen deposition in liver and muscle during intraduodenal glucose was calculated as the fraction of glycogen derived from blood

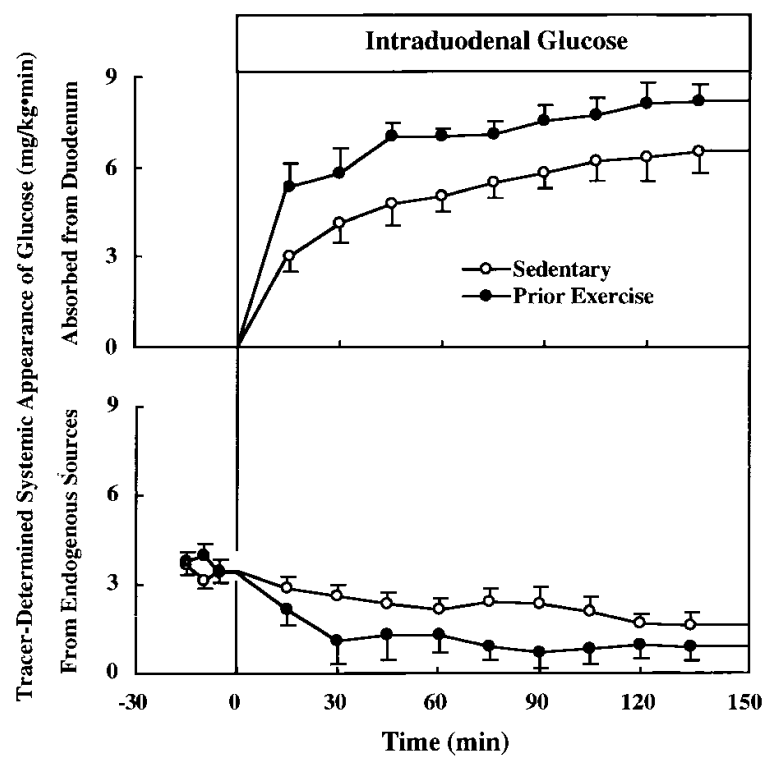

Figure 3. Systemic appearance of glucose from the intestine (top) and liver (bottom) during an intraduodenal glucose load $(8 \mathrm{mg} / \mathrm{kg} \cdot \mathrm{min})$ in sedentary (open circles) and exercised (closed circles) dogs. Data are mean \pm SE; $n=8$ and 6 sedentary and exercised dogs, respectively. Systemic appearance of intraduodenal glucose was significantly higher after exercise throughout the intraduodenal glucose infusion period $(P<0.02-0.01)$. Endogenous glucose production was suppressed to a greater extent during intraduodenal glucose in exercised dogs at $\mathrm{t}=30,45,75,90$, and $105 \min (P<0.05-0.005)$.

glucose (mean $\left[{ }^{14} \mathrm{C}\right]$ glucose precursor SA during the intraduodenal infusion $/\left[{ }^{14} \mathrm{C}\right]$ glycogen SA) multiplied by the glycogen content of the liver. Cold and radioactive liver glycogen concentrations were the mean of biopsy measurements from all liver lobes.

Statistics were performed using SuperAnova (Abacus Concepts, Inc., Berkeley, CA) on a Macintosh PowerPC. Statistical comparisons between groups and over time were made using ANOVA designed to account for repeated measures. Specific time points were examined for significance using contrasts solved by univariate repeated measures. Statistics are reported in the corresponding table or figure legend for each variable. Differences were considered significant when $P$ values were $<0.05$. Data are expressed as mean \pm SE.

\section{Results}

Arterial plasma hormone levels. Intraduodenal glucose elicited a fourfold increase in arterial plasma insulin levels which was equivalent in sedentary and exercised dogs (Fig. 1). Glucagon levels (Fig. 1) were significantly elevated after exercise $(62 \pm 6 \mathrm{pg} / \mathrm{ml})$ compared with sedentary animals $(39 \pm 2 \mathrm{pg} / \mathrm{ml})$. Glucagon levels remained elevated at $\mathrm{t}=15$ and $30 \mathrm{~min}$ of intraduodenal glucose. Table I shows that the arterial plasma cortisol, norepinephrine, and epinephrine levels were elevated after exercise before the intraduodenal glucose infusion. Differences in cortisol and epinephrine levels between exercised and sedentary animals were significant $(P<0.05)$. Although there was a tendency for cortisol to be higher during the intraduodenal glucose load, no significant differences between groups were present.

Arterial plasma glucose levels and whole body glucose fluxes. Arterial plasma glucose was not significantly different in sedentary and exercised dogs before the intraduodenal glu- 


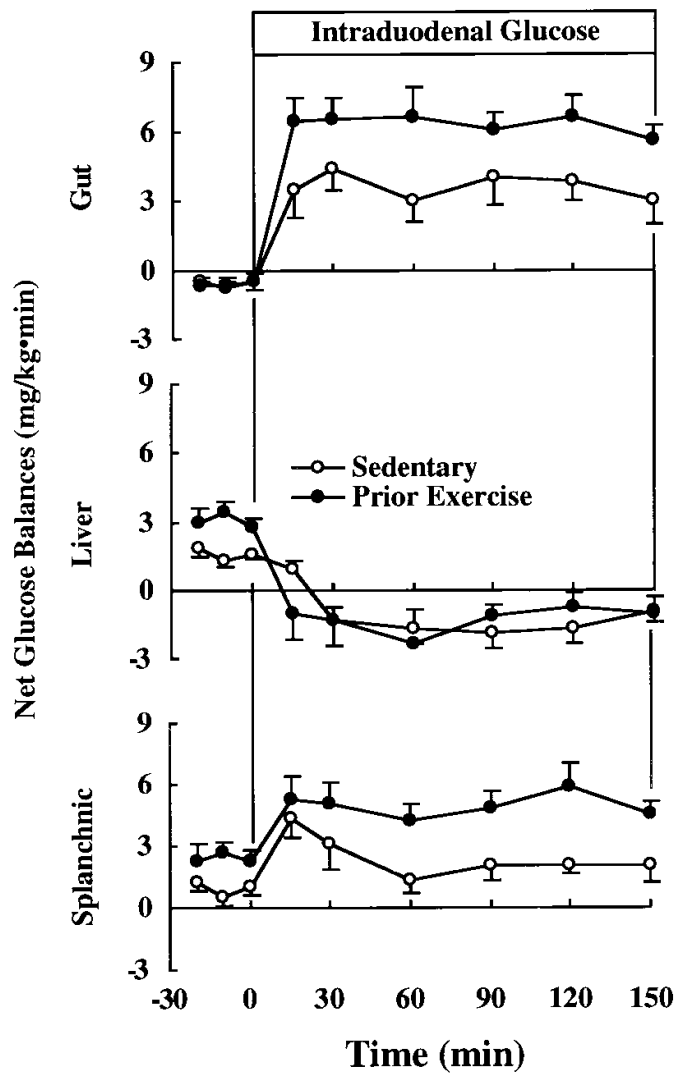

Figure 4. Net gut (top), hepatic (middle), and splanchnic (bottom) glucose balances during an intraduodenal glucose load $(8 \mathrm{mg} / \mathrm{kg}$. min) in sedentary (open circles) and exercised (closed circles) dogs. Data are mean \pm SE; $n=6$ dogs in each protocol. Net gut glucose output during intraduodenal glucose was greater after exercise at $\mathrm{t}=15$, 60,120 , and $150 \mathrm{~min}(P<0.05-0.005)$. Net hepatic glucose output was greater in the basal period after exercise $(P<0.02)$. Net splanchnic glucose output was greater after exercise at $\mathrm{t}=-10,30,60,90,120$, and $150 \mathrm{~min}(P<0.02-0.01)$.

cose infusion (Fig. 2). It rose to a greater extent with intraduodenal glucose in exercised dogs. The larger increase in arterial glucose after exercise occurred due to a more rapid increase in total $R_{\mathrm{a}}$ as compared with sedentary dogs in the first 15 min. Glucose clearance $\left(R_{\mathrm{d}}\right.$ divided by arterial glucose level) increased similarly in sedentary and exercised dogs over that same period.

Splanchnic glucose metabolism. The exaggerated initial increase in total glucose appearance after exercise was due to a greater systemic appearance of intraduodenal glucose (Fig. 3). The systemic appearance of intraduodenal glucose was $\sim 2$ $\mathrm{mg} / \mathrm{kg} \cdot \mathrm{min}$ greater after exercise throughout the infusion period. Splanchnic glucose output was elevated in exercised animals compared with the sedentary group before the intraduodenal infusion $(2.4 \pm 0.4$ vs. $0.9 \pm 0.3 \mathrm{mg} / \mathrm{kg} \cdot \mathrm{min})$ and rose to a greater extent during infusion $(4.5 \pm 0.7$ vs. $2.1 \pm 0.9$ $\mathrm{mg} / \mathrm{kg} \cdot \min$ at $\mathrm{t}=150 \mathrm{~min}$ ) (Fig. 4).

The reason for the increases in the systemic appearance of intraduodenal glucose and net splanchnic glucose output after exercise relates to effects of exercise on gut and liver glucose balances. Net gut glucose output during intraduodenal glucose was accelerated by prior exercise reaching a rate of $5.6 \pm 0.7 \mathrm{mg} / \mathrm{kg}$ - $\min$ at $\mathrm{t}=150 \mathrm{~min}$ compared with a rate of $3.0 \pm 1.0 \mathrm{mg} / \mathrm{kg}$. min in sedentary animals (Fig. 4). Net hepatic glucose output was $\sim 70 \%$ greater in the control period after exercise compared with rest (Fig. 4). Nevertheless, net hepatic glucose uptake was not significantly different in response to intraduodenal glucose. Fig. 3 shows that endogenous $R_{\mathrm{a}}$, while similar before intraduodenal glucose in the two protocols, was reduced to a lower rate $(\sim 1 \mathrm{mg} / \mathrm{kg} \cdot \mathrm{min})$ during intraduodenal glucose after exercise. The hepatic glucose load and the portal vein to arterial glucose gradient, both stimulators of hepatic glucose uptake, were unaffected and increased by prior exercise, respectively (Table II). Although the tracer-determined systemic appearance of intraduodenal glucose is determined by the gut and hepatic glucose balances, the response of these variables determined by arteriovenous differences is somewhat different than the tracer-determined variable. The balances rapidly obtain plateau rates during glucose loading, while the tracerdetermined systemic appearance of intraduodenal glucose continues to rise gradually after an initial rapid rise. The gradual rise phase may reflect the contribution of $\left[{ }^{14} \mathrm{C}\right]$ glucose recycling.

Hepatic glucose oxidation (Fig. 5) was significantly greater in response to intraduodenal glucose in sedentary compared with exercised dogs reaching rates of $0.78 \pm 0.14$ and $0.40 \pm 0.13$ $\mathrm{mg} / \mathrm{kg} \cdot \mathrm{min}$, respectively, during the last $60 \mathrm{~min}$ of intraduodenal glucose.

Limb glucose metabolism. Net limb glucose uptake (Fig. 6) was elevated during the control period approximately twofold, in the exercised dogs. During intraduodenal glucose infusion it

Table II. Arterial Plasma Concentration and Portal-Vein Plasma Glucose Gradient in Sedentary and Exercised Dogs before and during Intraduodenal Glucose

\begin{tabular}{|c|c|c|c|c|c|c|c|}
\hline & \multirow[b]{2}{*}{ Pre-glucose load } & \multicolumn{6}{|c|}{ Intraduodenal glucose } \\
\hline & & $15 \mathrm{~min}$ & $30 \mathrm{~min}$ & $60 \mathrm{~min}$ & $90 \mathrm{~min}$ & $120 \mathrm{~min}$ & $150 \mathrm{~min}$ \\
\hline \multicolumn{8}{|c|}{ Hepatic glucose load $(\mathrm{mg} / \mathrm{kg} \cdot \mathrm{min})$} \\
\hline Sedentary & $23 \pm 2$ & $34 \pm 4$ & $38 \pm 4$ & $38 \pm 2$ & $39 \pm 4$ & $37 \pm 3$ & $33 \pm 3$ \\
\hline Prior exercise & $20 \pm 1$ & $35 \pm 5$ & $36 \pm 5$ & $39 \pm 4$ & $36 \pm 3$ & $36 \pm 3$ & $33 \pm 4$ \\
\hline \multicolumn{8}{|c|}{ Arterial-portal vein blood glucose (mg/dl) } \\
\hline Sedentary & $3 \pm 1$ & $-13 \pm 4$ & $-16 \pm 3$ & $-11 \pm 4$ & $-15 \pm 4$ & $-15 \pm 3$ & $-13 \pm 5$ \\
\hline Prior exercise & $3 \pm 1$ & $-34 \pm 6^{*}$ & $-31 \pm 3^{*}$ & $-30 \pm 7 *$ & $-28 \pm 3 *$ & $-29 \pm 3 *$ & $-29 \pm 4 *$ \\
\hline
\end{tabular}

Data are mean \pm SE. $n=6$ in both protocols. *Values are significantly different compared with sedentary animals $(P<0.001)$. 


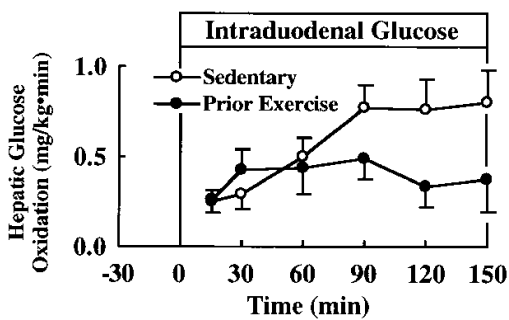

Figure 5. Hepatic oxidative glucose metabolism during an intraduodenal glucose load $(8 \mathrm{mg} /$ $\mathrm{kg} \cdot \mathrm{min})$ in sedentary (open circles) and exercised (closed circles) dogs. Data are mean \pm $\mathrm{SE} ; n=6$ dogs in each protocol. Hepatic glucose oxidation was greater after exercise at $\mathrm{t}=90,120$, and $150 \mathrm{~min}$ $(P<0.05-0.002)$.

increased to $19 \pm 3$ and $37 \pm 7 \mathrm{mg} / \mathrm{min}$ at $\mathrm{t}=150 \mathrm{~min}$ in sedentary and exercised dogs, respectively. The elevated net limb glucose uptake was largely due to an elevated net limb fractional glucose extraction (Fig. 6). Greater than $90 \%$ of the glucose taken up by the limb during the intraduodenal glucose infusion was metabolized nonoxidatively in both groups (Fig. 7). In addition, the added glucose taken up by the limb after exercise was metabolized nonoxidatively as rates of $35 \pm 7 \mathrm{mg} / \mathrm{min}$ were achieved compared with rates of only $18 \pm 3 \mathrm{mg} / \mathrm{min}$ in sedentary animals. Limb glucose oxidation was not significantly affected by prior exercise (Fig. 7).

Arterial blood levels and splanchnic and limb balances and lactate. Arterial blood lactate was similar in both groups before and during the intraduodenal glucose infusion (Fig. 8). Slight net gut lactate output was present in both protocols be-

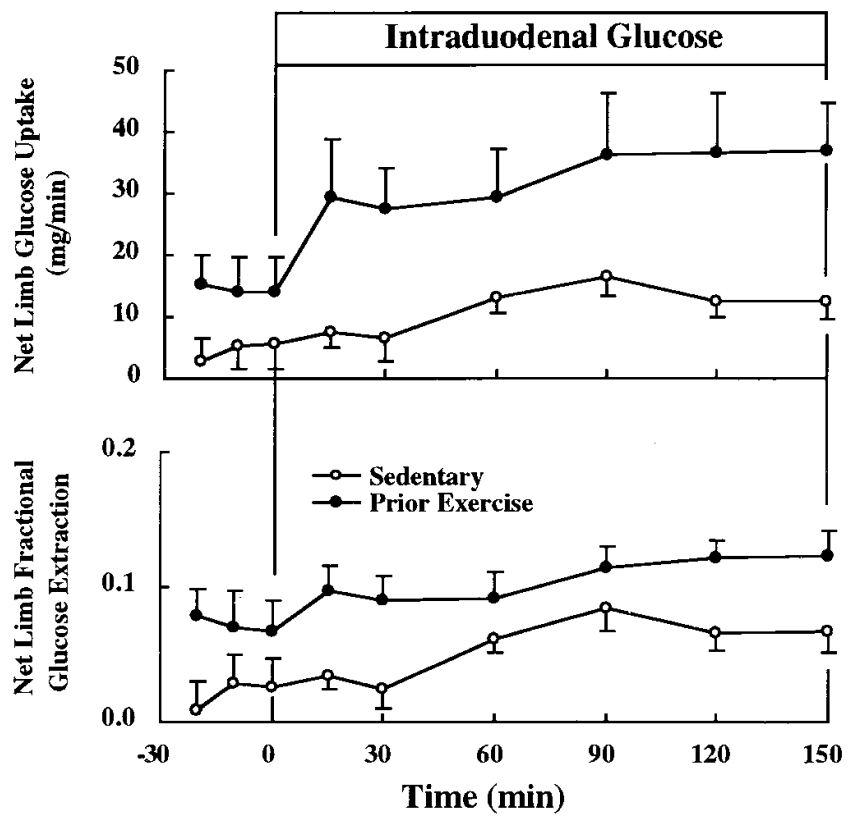

Figure 6. Net limb glucose uptake (top) and fractional extraction (bottom) during an intraduodenal glucose load $(8 \mathrm{mg} / \mathrm{kg} \cdot \mathrm{min})$ in sedentary (open circles) and exercised (closed circles) dogs. Data are mean \pm SE; $n=8$ and 7 sedentary and exercised dogs, respectively. Net limb glucose uptake was significantly greater after exercise throughout the intraduodenal glucose infusion period $(P<0.02$ $0.001)$. Net limb fractional extraction was higher after exercise at $\mathrm{t}=$ $-20,15,30,120$, and $150 \mathrm{~min}(P<0.05-0.01)$.

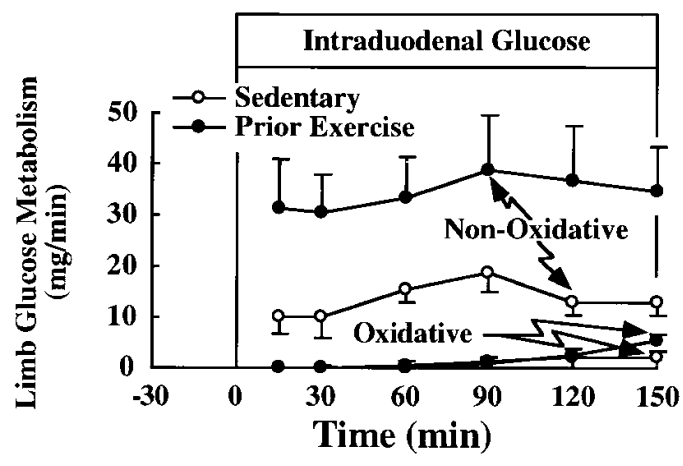

Figure 7. Limb oxidative and nonoxidative glucose metabolism during an intraduodenal glucose load $(8 \mathrm{mg} / \mathrm{kg} \cdot \mathrm{min})$ in sedentary (open circles) and exercised (closed circles) dogs. Data are mean \pm SE; $n=8$ and 7 sedentary and exercised dogs, respectively. Limb nonoxidative glucose metabolism was higher in exercised dogs throughout the intraduodenal glucose infusion $(P<0.05-0.01)$.

fore and during intraduodenal glucose (Fig. 8). Before intraduodenal glucose, net hepatic lactate output was present in sedentary animals $(0.53 \pm 0.49 \mathrm{mg} / \mathrm{kg} \cdot \mathrm{min})$, while net hepatic lactate uptake was present $(-0.49 \pm 0.08 \mathrm{mg} / \mathrm{kg} \cdot \mathrm{min})$ in the previously exercised animals. In response to intraduodenal glucose, the liver consistently produced lactate at similar rates in both groups. Before the intraduodenal glucose infusion, net limb lactate balance showed a reciprocal pattern compared with net hepatic lactate balance (Fig. 8). Net limb lactate uptake was present in sedentary animals, while net lactate release was evident after exercise. In response to intraduodenal glu-

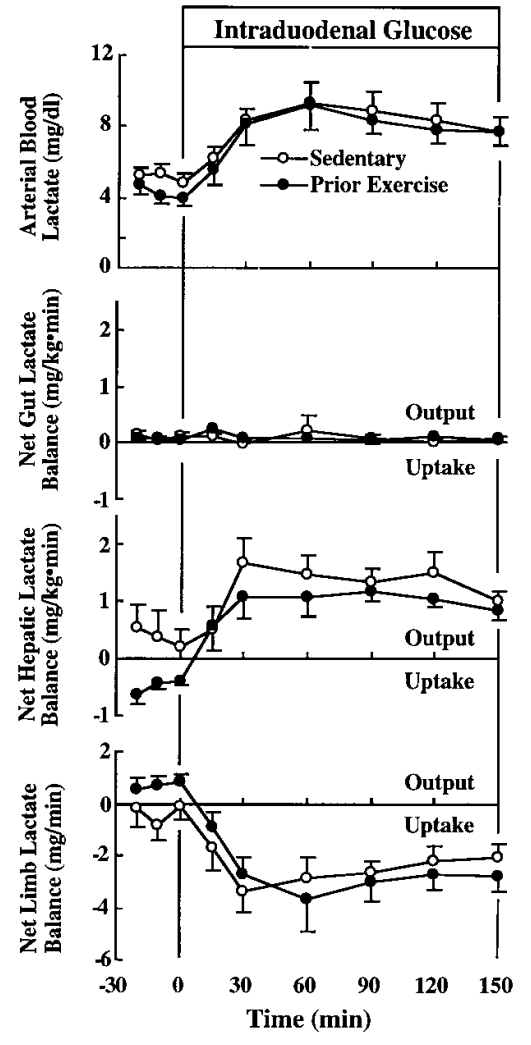

Figure 8. Arterial blood lactate levels (top), net gut (second from top), net hepatic (third from top), and net limb lactate balances (bottom) during an intraduodenal glucose load $(8 \mathrm{mg} / \mathrm{kg}$. min) in sedentary (open circles) and exercised (closed circles) dogs. Data are mean \pm SE; $n=8$ and 7 sedentary and exercised dogs in top and bottom panels and $n=6$ and 6 in the middle two panels. 
Table III. Arterial Blood Glycerol and Plasma NEFA Concentrations in Sedentary and Exercised Dogs before and during Intraduodenal Glucose

\begin{tabular}{|c|c|c|c|c|c|c|c|}
\hline & \multirow[b]{2}{*}{ Pre-glucose load } & \multicolumn{6}{|c|}{ Intraduodenal glucose } \\
\hline & & $15 \mathrm{~min}$ & $30 \mathrm{~min}$ & $60 \mathrm{~min}$ & $90 \mathrm{~min}$ & $120 \mathrm{~min}$ & $150 \mathrm{~min}$ \\
\hline \multicolumn{8}{|l|}{ Glycerol $(\mu \mathrm{M})$} \\
\hline Sedentary & $68 \pm 4$ & $50 \pm 8$ & $37 \pm 3$ & $31 \pm 5$ & $32 \pm 4$ & $28 \pm 3$ & $28 \pm 4$ \\
\hline Prior exercise & $156 \pm 9 *$ & $78 \pm 8^{*}$ & $68 \pm 7 *$ & $51 \pm 5^{*}$ & $41 \pm 5$ & $40 \pm 4$ & $37 \pm 3$ \\
\hline \multicolumn{8}{|l|}{ NEFA $(\mu$ Eq/liter $)$} \\
\hline Sedentary & $855 \pm 106$ & $675 \pm 90$ & $351 \pm 43$ & $178 \pm 34$ & $143 \pm 18$ & $133 \pm 22$ & $148 \pm 28$ \\
\hline Prior exercise & $1566 \pm 134 *$ & $794 \pm 93$ & $441 \pm 42 *$ & $268 \pm 39 *$ & $194 \pm 36^{*}$ & $167 \pm 22$ & $152 \pm 24$ \\
\hline
\end{tabular}

Data are mean \pm SE. $n=8$ and 7 for sedentary and exercised animals, respectively. *Levels are significantly different compared with sedentary animals $(P<0.02-0.001)$.

cose, the limbs of sedentary and previously exercised dogs consumed lactate at equal rates $(\sim 3 \mathrm{mg} / \mathrm{min})$.

Arterial blood glycerol and plasma nonesterified fatty acid (NEFA) levels. Arterial glycerol levels (Table III) were significantly greater after exercise both before and during the intraduodenal glucose infusion. Arterial NEFA levels (Table III) were increased by approximately twofold after exercise. Although intraduodenal glucose led to a suppression in NEFA levels in both sedentary and exercised dogs, statistically higher values were still present at $\mathrm{t}=30,60$, and $90 \mathrm{~min}$ in dogs having exercised.

Liver and muscle glycogen levels, glycogen synthase activity, and glucose phosphorylating activity (glucokinase and hexokinase). Hepatic glycogen is depleted by $\sim 70 \%$ with the exercise protocol used in these studies (6). Table IV shows that liver glycogen levels are still reduced even after a 150 -min intraduodenal glucose infusion. The percentage of the total hepatic glycogen mass synthesized and the net rate of hepatic glycogen synthesis during the intraduodenal glucose infusion were not affected by prior exercise. Skeletal muscle glycogen was not significantly different in sedentary and exercised dogs after intraduodenal glucose. The fraction of muscle glycogen formed and the muscle glycogen synthetic rate during the intraduodenal glucose infusion were threefold higher in exercised dogs. Hepatic and skeletal muscle glycogen synthase activities in the presence and absence of glucose 6-phosphate (data not shown) and fractional velocity (Table V) after intraduodenal glucose were similar in sedentary and exercised dogs. Moreover, liver glucokinase and skeletal muscle hexokinase activities after intraduodenal glucose infusion were unaffected by prior exercise.

Blood flow measurements. Blood flows in the portal vein and hepatic artery were not significantly influenced by prior exercise or intraduodenal glucose (Table VI). Splanchnic blood flow measured using dye extraction techniques was not significantly different from and was always within $20 \%$ of the sum of portal vein and hepatic artery blood flow measurements assessed using Doppler flow probes. Mean external iliac artery blood flow tended to be higher after exercise compared with sedentary dogs (Table VI). However, differences were insignificant. Blood flow through this vessel was not influenced in either protocol by intraduodenal glucose.

\section{Discussion}

These results show how prior exercise affects the partitioning of ingested (intraduodenal) glucose between splanchnic bed and skeletal muscle. The rate that glucose escaped the splanchnic bed was $\sim 2.5 \mathrm{mg} / \mathrm{kg} \cdot \min$ higher during intraduodenal glucose in dogs having undergone prior exercise as compared with those that were previously sedentary. This finding is apparent from two independent techniques. Exercised dogs had a greater net splanchnic glucose output as demonstrated using arterial-hepatic venous differences (Fig. 4) and an increased systemic appearance of intraduodenal glucose determined by tracing the rate of appearance of $\left[{ }^{14} \mathrm{C}\right]$ glucose mixed into the

Table IV. Liver and Muscle Glycogen (mg/gram of tissue), Percentage of Total Glycogen Formed during the Intraduodenal Glucose Infusion, and Rate of Glycogen Synthesis during the Intraduodenal Glucose Infusion (mg/[gram of tissue $150 \mathrm{~min}]$ )

\begin{tabular}{lccc}
\hline & Total glycogen & Percentage of glycogen formed during intraduodenal glucose & Glycogen synthesis during intraduodenal glucose \\
\hline Liver & & & $4.1 \pm 1.1(0.81 \pm 0.22)$ \\
$\quad$ Sedentary & $38.3 \pm 4.8$ & $11 \pm 3$ & $3.9 \pm 1.0(0.64 \pm 0.17)$ \\
$\quad$ Prior exercise & $26.2 \pm 1.2^{*}$ & $15 \pm 4$ & $0.5 \pm 0.1$ \\
Muscle & & & $1.4 \pm 0.3^{*}$ \\
Sedentary & $6.2 \pm 0.9$ & $9 \pm 2$ & $27 \pm 5^{*}$ \\
$\quad$ Prior exercise & $5.3 \pm 0.8$ & & \\
\hline
\end{tabular}

Data are mean \pm SE. $n=8$ sedentary and $n=6$ exercised dogs. Values in parentheses are the glycogen formed from absorbed glucose expressed in $\mathrm{mg} / \mathrm{kg} \cdot \mathrm{min}$. *Values are significantly different compared with sedentary animals $(P<0.02-0.005)$. 
Table V. Liver and Skeletal Muscle Glycogen Synthase Activity (Fractional Velocity) and Glucose Phosphorylating Activity (1 $\mathrm{mU} \mathrm{NADPH} /[\mathrm{mg}$ protein.min])

\begin{tabular}{lccccc}
\hline & \multicolumn{2}{c}{ Liver } & & \multicolumn{2}{c}{ Skeletal muscle } \\
\cline { 2 - 3 } \cline { 5 - 5 } & Glycogen synthase & Glucokinase & & Glycogen synthase & Hexokinase \\
\hline Sedentary & $0.19 \pm 0.02$ & $239 \pm 23$ & & $0.46 \pm 0.01$ & $71 \pm 5$ \\
Prior exercise & $0.19 \pm 0.03$ & $206 \pm 12$ & & $0.46 \pm 0.02$ & $67 \pm 6$ \\
& & & & \\
\hline
\end{tabular}

Data are mean \pm SE. Liver and skeletal muscle glycogen synthase activities were measured in six sedentary and five exercised dogs. Liver and skeletal muscle glucose phosphorylating activities, which correspond to glucokinase and hexokinase activities, respectively, were measured in six sedentary and seven exercised dogs. Liver values represent the mean of two separate biopsies and skeletal muscle values are the mean of three separate muscles of the hindlimb (gastrocnemius, flexor hallicus longus, and gracilis).

intraduodenal glucose infusate using $\left[{ }^{3} \mathrm{H}\right]$ glucose (Fig. 3). The physiological basis for the increased rates of net splanchnic glucose output and systemic appearance of intraduodenal glucose was an increase in intestinal glucose absorption in the previously exercised dogs. Whether this increase in intestinal glucose absorption is a result of a nonspecific increase in intestinal permeability that affects many nutrients or is specific to intestinal transport is unclear. The two- to threefold greater net limb glucose uptake and glycogen synthesis shows that the fate of the added glucose escaping the splanchnic bed is the previously working muscle. These findings are consistent with a study that showed that twofold more glucose escapes the splanchnic bed after a 100-gram oral glucose load in humans after exhaustive exercise and $\sim 66 \%$ of that which escapes is channeled into muscle glycogen (26). Furthermore, these data explain why prior exercise, well known to increase muscle insulin sensitivity and glucose effectiveness, generally does not improve (1-3) and may even worsen $(4,5,27)$ oral glucose tolerance. This is reflected in the present study by the $\sim 15 \mathrm{mg} / \mathrm{dl}$ greater increase in arterial plasma glucose during intraduodenal glucose in the postexercise state.

Net hepatic glucose uptake during intraduodenal glucose was unaltered by prior exercise and, therefore, did not contribute to the increased net splanchnic glucose output. However, closer examination showed that intraduodenal glucose exerted a greater suppressive effect on endogenous $R_{\mathrm{a}}$ after exercise. By taking the difference between the tracer-determined total $R_{\mathrm{a}}$ and the systemic glucose appearance derived from the intestinal load it was evident that the rate of endogenous $R_{\mathrm{a}}$ was suppressed more effectively and comprised a smaller percentage of the total $R_{\mathrm{a}}$ in the postexercise state. Arterial plasma glucose was $\sim 15 \mathrm{mg} / \mathrm{dl}$ greater and, perhaps more significantly, the portal vein plasma glucose was $\sim 30 \mathrm{mg} / \mathrm{dl}$ higher in exercised compared with sedentary dogs. It is possible that higher glucose levels may have resulted in a greater suppression of endogenous $R_{\mathrm{a}}$ after exercise (28). Differences in plasma insulin levels did not cause the greater suppression of endogenous $R_{\mathrm{a}}$ since the levels of this hormone were similar in sedentary and exercised dogs. It is possible that, like skeletal muscle, the liver (or kidney) may be more insulin sensitive after exercise. Studies in humans suggest that tracer-determined endogenous $R_{\mathrm{a}}$ is more easily suppressed by hyperinsulinemia after exercise $(29,30)$. However, these findings have to be considered in light of problems in the interpretation of tracer data during insulin clamps (31). The nature of the tracer problem is such that a greater error might be predicted in individuals having conducted prior exercise since their glucose turnover will be higher and the endogenous $R_{\mathrm{a}}$ will be a smaller percentage of total glucose flux. Although arterial glucagon levels were actually higher in exercised dogs, they fell to a greater extent in response to intraduodenal glucose in this group. Therefore it is possible that the greater suppression of endogenous $R_{\mathrm{a}}$ resulted from the greater decrement in this hormone. In a sense, the greater suppression of endogenous $R_{\mathrm{a}}$ during intraduode-

Table VI. Portal Vein, Hepatic Artery, Dye-Determined Splanchnic Blood Flow and External Iliac Artery Blood Flows in Sedentary and Exercised Dogs before and during Intraduodenal Glucose

\begin{tabular}{|c|c|c|c|c|c|c|c|}
\hline & \multirow[b]{2}{*}{ Pre-glucose load } & \multicolumn{6}{|c|}{ Intraduodenal glucose } \\
\hline & & $15 \mathrm{~min}$ & $30 \mathrm{~min}$ & $60 \mathrm{~min}$ & $90 \mathrm{~min}$ & $120 \mathrm{~min}$ & $150 \mathrm{~min}$ \\
\hline \multicolumn{8}{|c|}{ Portal vein $(\mathrm{ml} / \mathrm{kg} \cdot \mathrm{min})$} \\
\hline Sedentary & $25 \pm 3$ & $27 \pm 2$ & $28 \pm 2$ & $28 \pm 2$ & $27 \pm 2$ & $26 \pm 2$ & $25 \pm 2$ \\
\hline Prior exercise & $23 \pm 1$ & $22 \pm 3$ & $21 \pm 2$ & $23 \pm 2$ & $22 \pm 2$ & $22 \pm 2$ & $20 \pm 2$ \\
\hline \multicolumn{8}{|c|}{ Hepatic artery $(\mathrm{ml} / \mathrm{kg} \cdot \mathrm{min})$} \\
\hline Sedentary & $4.9 \pm 0.4$ & $4.9 \pm 0.3$ & $5.2 \pm 0.3$ & $5.3 \pm 0.3$ & $5.3 \pm 0.3$ & $5.2 \pm 0.3$ & $4.9 \pm 0.3$ \\
\hline Prior exercise & $4.7 \pm 0.5$ & $4.3 \pm 0.5$ & $4.3 \pm 0.6$ & $4.8 \pm 0.6$ & $4.7 \pm 0.6$ & $4.6 \pm 0.6$ & $4.3 \pm 0.6$ \\
\hline \multicolumn{8}{|c|}{ Dye-determined total splanchnic $(\mathrm{ml} / \mathrm{kg} \cdot \mathrm{min})$} \\
\hline Sedentary & $34 \pm 4$ & $31 \pm 3$ & $32 \pm 5$ & $32 \pm 4$ & $35 \pm 4$ & $31 \pm 3$ & $28 \pm 4$ \\
\hline Prior exercise & $29 \pm 3$ & $24 \pm 2$ & $24 \pm 2$ & $25 \pm 3$ & $23 \pm 2$ & $24 \pm 3$ & $23 \pm 1$ \\
\hline \multicolumn{8}{|c|}{ External iliac artery $(\mathrm{ml} / \mathrm{min})$} \\
\hline Sedentary & $221 \pm 25$ & $212 \pm 20$ & $214 \pm 22$ & $205 \pm 15$ & $199 \pm 16$ & $200 \pm 17$ & $218 \pm 20$ \\
\hline Prior exercise & $251 \pm 47$ & $251 \pm 52$ & $257 \pm 52$ & $245 \pm 48$ & $252 \pm 49$ & $257 \pm 45$ & $248 \pm 40$ \\
\hline
\end{tabular}

Data are mean \pm SE. Portal vein, hepatic artery, and external iliac artery blood flows were measured using a Doppler technique, while dye-determined splanchnic blood flow was measured using a constant infusion of indocyanine green. $n=6$ for portal vein and hepatic artery in both protocols. $n=8$ and 7 for external iliac artery in sedentary and exercised animals, respectively. 
nal glucose after exercise is a paradox since the purpose of other splanchnic adaptations to prior exercise described in these studies is to facilitate net splanchnic glucose release.

Similar rates of net hepatic glucose uptake in sedentary and exercised dogs during intraduodenal glucose, coupled to a greater suppression of endogenous $R_{\mathrm{a}}$ in exercised dogs, imply that the absolute rate of hepatic glucose uptake was also attenuated. However, this variable was impossible to quantify. The measurement of hepatic glucose uptake requires either the accurate determination of hepatic balance of isotopic glucose or calculation of the difference between endogenous $R_{\mathrm{a}}$ and net hepatic glucose balance. Both measurements are limited by high inherent variabilities. Furthermore, the second method for calculating hepatic glucose uptake, which requires that total $R_{\mathrm{a}}$ be subtracted from net hepatic glucose balance, will be in error due to the contribution of the kidney to total $R_{\mathrm{a}}(\sim 25 \%)$ $(32,33)$. The possibility that total hepatic glucose uptake is attenuated during intraduodenal glucose after exercise is interesting in light of the fact that plasma insulin and hepatic glucose load were not significantly different and that the magnitude of the arterial-portal vein glucose gradient, an independent stimulator of net hepatic glucose uptake, was actually increased about twofold. Aspects of each of these factors that control net hepatic glucose uptake are worth noting. It at first seems surprising that arterial insulin levels and hepatic glucose load are no different even though arterial glucose was higher in exercised dogs. The similar insulin levels despite higher glucose levels during glucose loading in exercised dogs are consistent with the well-described blunting effect of prior exercise on glucose-induced insulin secretion (8). Hepatic glucose load was no higher despite elevated glucose levels as hepatic blood flow tended to be greater, although insignificantly, compensating for the lower plasma glucose in sedentary dogs. Although the arterial-portal vein glucose gradient was clearly higher when exercise preceded the glucose load, it should be noted that hepatic glucose extraction is relatively insensitive to gradients in the range observed between sedentary and exercised dogs ( 15-30 mg/dl) (34). Very little is known about how acute exercise affects hepatic glucose uptake. An attenuated hepatic glucose uptake is consistent with the report that habitual physical activity decreases insulin's effect on glucose clearance by the perfused liver (35). Glucagon has been shown to antagonize net hepatic glucose uptake in dogs (36). The higher glucagon levels in exercised dogs may have contributed to an attenuation of hepatic glucose uptake. We speculated that at the cellular level differences in hepatic glucose uptake may be due to an effect of prior exercise on the enzyme that catalyzes glucose phosphorylation, glucokinase. Although the activity of this enzyme was reduced by $14 \%$, differences were insignificant.

The physiological importance of the adaptations at the liver due to prior exercise is difficult to evaluate since prior exercise did not affect net hepatic glucose balance during intraduodenal glucose. Regardless, distinguishing hepatic glucose uptake from net hepatic glucose balance is necessary to understand the apparent incongruent behavior of net limb glucose uptake and whole body $R_{\mathrm{d}}$. Net limb glucose uptake during intraduodenal glucose was increased by approximately twofold by prior exercise, while $R_{\mathrm{d}}$ was only slightly increased $(0.5-1.0 \mathrm{mg} / \mathrm{kg} \cdot \mathrm{min} ; P>0.05 ; \mathrm{NS})$. If one considers an average dog weight to be $20 \mathrm{~kg}$ (25) and assumes that all four limbs are equal in weight (forelimbs are $\sim 80 \%$ of the mass of the hindlimb) and respond equally to exercise, one can estimate that whole body $R_{\mathrm{d}}$ should be $\sim 3.0 \mathrm{mg} / \mathrm{kg} \cdot \min$ greater during intraduodenal glucose in the postexercise state. The difference between $R_{\mathrm{d}}$ projected from limb arteriovenous data and the actual rate calculated using isotope dilution might possibly be explained by differences in hepatic glucose uptake. As described in the preceding paragraph, the differences between net hepatic glucose uptake and endogenous $R_{\mathrm{a}}$ during intraduodenal glucose suggest indirectly that total hepatic glucose uptake is attenuated by prior exercise. A rough estimate indicates that this variable is reduced by $\sim 2.0-2.5 \mathrm{mg} / \mathrm{kg} \cdot \mathrm{min}$. This is enough to mask the predicted increase in $R_{\mathrm{d}}$ due to excess limb glucose uptake.

Liver glycogen accumulated at similar rates in sedentary and exercised dogs. This is consistent with the demonstration that hepatic glycogen synthase activity after intraduodenal glucose was unaffected by prior exercise. The sums of net hepatic glycogen synthesis and lactate output for sedentary and exercised dogs were 2.1 and $1.6 \mathrm{mg} / \mathrm{kg} \cdot \mathrm{min}$, respectively, and hepatic glucose oxidation averaged 0.6 and $0.4 \mathrm{mg} / \mathrm{kg} \cdot \mathrm{min}$ during glucose loading. Differences in hepatic glucose oxidation were due entirely to greater rates during the last hour of intraduodenal glucose in sedentary dogs. It can be estimated from these data that $\sim 75 \%$ of the glucose taken up by the liver in both groups was metabolized by nonoxidative processes.

Prior exercise increased net limb glucose uptake during intraduodenal glucose by causing a larger increase in arterial glucose and, consequently, limb glucose load, as well as by increasing limb fractional glucose extraction. This finding of increased glucose uptake by skeletal muscle supports numerous other studies conducted in rat and humans (for review see reference 37). The increase in limb fractional glucose extraction corresponded to an approximately fourfold increase in insulin in both groups. The greater increase in fractional extraction in exercised animals occurred even though insulin levels were no greater than in sedentary controls. Differences in limb fractional glucose extraction were probably due to increases in skeletal muscle insulin sensitivity $(9,38-41)$ and insulin-independent glucose uptake $(9,38,42)$.

The vast majority of glucose taken up by the hindlimb was metabolized nonoxidatively in both sedentary and exercised animals. These data also show that the added glucose taken up in the postexercise state, beyond that seen in sedentary animals, was metabolized nonoxidatively. The improved capacity of exercised animals to metabolize glucose nonoxidatively is consistent with numerous other studies (38, 39, 41, 43-45). While both arteriovenous difference and biopsy methods indicated that two- to threefold more glucose was disposed of by nonoxidative pathways after exercise, the absolute values given by the two methods were markedly different. Arteriovenous differences of glucose, lactate, and ${ }^{14} \mathrm{CO}_{2}$ were used to calculate nonoxidative metabolism of glucose and lactate (see Methods) and showed that $\sim 2.2$ and 4.5 grams of glucose was disposed of nonoxidatively during intraduodenal glucose by the hindlimb of sedentary and exercised dogs, respectively. This differs markedly from values of 0.4 and 0.9 grams for net glycogen deposition for sedentary and exercised dogs measured using biopsy methods in hindlimb skeletal muscle (assuming that hindlimb is 660 grams of skeletal muscle [25]). Clearly the two variables measure unique parameters and it is reasonable to expect differences. For example, values for nonoxidative metabolism measured with arteriovenous differences reflect all tissues of the entire hindlimb, while net glycogen 
deposition obtained from muscle biopsies is calculated only for the portion of the hindlimb that is skeletal muscle. Since adipocyte glucose uptake is sensitized by prior exercise to the stimulatory effects of insulin, some of the difference may be ascribed to glucose taken up by these cells and used for triglyceride synthesis (46). Furthermore, nonoxidative metabolism assessed with arteriovenous differences also includes the release of glucose metabolites from the hindlimb. Lactate is actually consumed during intraduodenal glucose by the dog hindlimb and therefore is not one of these metabolites. It is possible that a comprehensive assessment of amino acid release will show that additional glucose carbon is released in this form. Finally, it is likely that some of the radioactive carbons are lost due to the capacitance of metabolic intermediate pools and the equilibration of ${ }^{14} \mathrm{C}$-compounds within these pools. This will result in an underestimation of ${ }^{14} \mathrm{CO}_{2}$ release and glucose plus lactate oxidation and an overestimation of nonoxidative glucose plus lactate metabolism. Even with methodological differences in mind, the magnitude of the differences in results obtained using these techniques is surprising and warrants further examination.

Intraduodenal glucose load resulted in an increase in arterial lactate, net splanchnic (and hepatic) lactate output, and net hindlimb lactate uptake in both groups. This is similar to the response that occurs in human subjects. After an oral glucose load, the splanchnic bed releases (or consumes less if the oral glucose load is small) lactate in humans (47-49). The increase in hindlimb lactate uptake during intraduodenal glucose in dogs is consistent with the demonstration that oral glucose is accompanied by an increase in net lactate uptake by the human forearm (50). It is important to recognize that the liver of the overnight-fasted dog usually produces lactate, while the splanchnic bed of overnight-fasted human is characterized by net lactate consumption. This difference is probably related to the shorter time needed for meal absorption in humans (mixed meal absorption time of $\sim 6$ vs. $16 \mathrm{~h}$ ). This, in effect, leads to a more gluconeogenic state at any given postmeal interval in humans.

Prior exercise facilitates glucose storage as glycogen in skeletal muscle. It is well known that adaptations at the muscle that result in increased sensitivity to insulin and insulin-independent processes are an important part of this response. The results of the experiments presented here show that the increase in the ability of previously working muscle to store glycogen is not simply a result of changes at the muscle itself. Specifically, in the postexercise state glucose is absorbed more rapidly from the intestine resulting in a greater net rate of splanchnic glucose release and an exaggerated rise in circulating glucose. On the other hand, net hepatic glucose uptake is no different from sedentary animals. The shift in the partitioning of absorbed glucose from splanchnic bed to skeletal muscle after exercise results in a threefold greater rate of net muscle glycogen deposition in the absence of increased net hepatic glycogen deposition. Finally, the ability of the gut and liver to adapt to physical activity, and perhaps other changes in metabolic or nutritional state, emphasizes that splanchnic glucose metabolism is a major factor in determining oral glucose tolerance.

\section{Acknowledgments}

The authors are grateful to Wanda Snead, Pamela Venson, Eric Allen, Thomas Becker, Robert Allison, and Robert Wilson for excellent technical assistance.
This work was supported by National Institutes of Health grant RO1 DK50277 and Diabetes Research and Training Center grant 5 P60 DK20593.

\section{References}

1. Maehlum, S., and L. Hermansen. 1978. Muscle glycogen concentration during recovery after prolonged severe exercise in fasting subjects. Scand. $J$. Clin. Lab. Invest. 38:557-560.

2. Ivy, J.L., B.A. Frishberg, S.W. Farrell, W.J. Miller, and W.M. Sherman. 1985. Effects of elevated and exercise-reduced muscle glycogen levels on insulin sensitivity. J. Appl. Physiol. 59:154-159.

3. Leblanc, J., A. Nadeau, D. Richard, and A. Tremblay. 1981. Studies on the sparing effect of exercise on insulin requirements in human subjects. Metab. Clin. Exp. 30:1119-1124.

4. Pestell, R.G., G.M. Ward, P. Galvin, J.D. Best, and F.P. Alford. 1993. Impaired glucose tolerance after endurance exercise is associated with reduced insulin secretion rather than altered insulin sensitivity. Metab. Clin. Exp. 42:277282 .

5. Pruett, E.D.R., and S. Oseid. 1970. Effect of exercise on glucose and insulin response to glucose infusion. Scand. J. Clin. Lab. Invest. 26:277-288.

6. Wasserman, D.H., P.E. Williams, D.B. Lacy, D.R. Green, and A.D. Cherrington. 1988. Importance of intrahepatic mechanisms to gluconeogenesis from alanine during prolonged exercise and recovery. Am. J. Physiol. 254: E518-E525.

7. Dufaux, B., G. Assmann, U. Order, A. Hoederath, and W. Hollmann. 1981. Plasma lipoproteins, hormones, and energy substrates during the first days after prolonged exercise. Int. J. Sports Med. 2:256-260.

8. James, D.E., K.M. Burleigh, E.W. Kraegen, and D.J. Chisholm. 1983. Effect of acute exercise and prolonged training on insulin response to intravenous glucose in vivo in rat. J. Appl. Physiol. 55:1660-1664.

9. Holloszy, J.O., S.H. Constable, and D.A. Young. 1986. Activation of glucose transport in muscle by exercise. Diabetes Metab. Rev. 1:409-423.

10. Hartley, C.J., H.G. Hanley, R.M. Lewis, and J.S. Cole. 1978. Synchronized pulsed Doppler blood flow and ultrasonic dimension measurement in conscious dogs. Ultrasound Med. Biol. 4:99-110.

11. Davis, M.A., P.E. Williams, and A.D. Cherrington. 1984. Effect of a mixed meal on hepatic lactate and gluconeogenic precursor metabolism in dogs. Am. J. Physiol. 247:E362-E369.

12. Wasserman, D.H., T. Mohr, P. Kelly, D.B. Lacy, and D. Bracy. 1992. The impact of insulin-deficiency on glucose fluxes and muscle glucose metabolism during exercise. Diabetes. 41:1229-1238.

13. Musch, T.I., D.B. Friedman, K.H. Pitetti, G.C. Haidet, J. Stray-Gundersen, J.H. Mitchell, and G.A. Ordway. 1987. Regional distribution of blood flow of dogs during graded dynamic exercise. J. Appl. Physiol. 63:2269-2276.

14. Lloyd, B., J. Burrin, P. Smythe, and K.G.M.M. Alberti. 1978. Enzymatic fluorometric continuous-flow assays for blood glucose, lactate, pyruvate, alanine, glycerol, and 3-hydroxybutyrate. Clin. Chem. 24:1724-1729.

15. Okajima, F., M. Chenowith, R. Rognstadt, A. Dunn, and J. Katz. 1981. Metabolism of 3H-and 14C-labeled lactate in starved rats. Biochem. J. 194:525540 .

16. Chan, T., and J. Exton. 1976. A rapid method for the determination of glycogen content and radioactivity in small quantities of tissue or isolated hepatocytes. Anal. Biochem. 71:96-105.

17. Golden, S., P.A. Wals, and J. Katz. 1977. An improved procedure for the assay of glycogen synthase and phosphorylase in rat liver homogenates. Anal. Biochem. 77:436-445.

18. O'Doherty, R.M., D.P. Bracy, H. Osawa, D.H. Wasserman, and D.K Granner. 1994. Rat skeletal muscle hexokinase II mRNA and activity are increased by a single bout of acute exercise. Am. J. Physiol. 266:E171-E178.

19. Morgan, C.R., and A.L. Lazarow. 1963. Immunoassay of insulin: two antibody system. Plasma insulin of normal, subdiabetic, and diabetic rats. Am. J. Med. Sci. 257:415-419.

20. Moghimzadeh, E., A. Nobin, and E. Rosengren. 1983. Fluorescence microscopical and chemical characterization of the adrenergic innervation in mammalian liver tissue. Cell Tissue Res. 230:605-613.

21. Debodo, R.D., R. Steele, N. Altszuler, A. Dunn, and J.S. Bishop. 1963 On the hormonal regulation of carbohydrate metabolism: studies with [14C]glucose. Recent Prog. Horm. Res. 19:445-448.

22. Cowan, J.S., and G. Hetenyi. 1971. Glucoregulatory responses in normal and diabetic dogs recorded by a new tracer method. Metab. Clin. Exp. 20:360 372 .

23. Greenway, C.V., and R.D. Stark. 1971. Hepatic vascular bed. Physiol. Rev. 51:23-65.

24. Sonne, B., and H. Galbo. 1985. Carbohydrate metabolism during and after exercise in rats: studies with radioglucose. J. Appl. Physiol. 59:1627-1639.

25. Wasserman, D.H., D.B. Lacy, D. Bracy, and P.E. Williams. 1992. Metabolic regulation in peripheral tissues and transition to increased gluconeogenic mode during prolonged exercise. Am. J. Physiol. 263:E345-E354.

26. Maehlum, S., P. Felig, and J. Wahren. 1978. Splanchnic glucose and 
muscle glycogen metabolism after glucose feeding during post-exercise recovery. Am. J. Physiol. 235:E255-E260.

27. King, D.S., P.J. Baldus, R.L. Sharp, L.D. Kesl, T.L. Feltmeyer, and M.S. Riddle. 1995. Time course for exercise-induced alterations in insulin action and glucose tolerance in middle-aged people. J. Appl. Physiol. 78:17-22.

28. Shulman, G.I., W.W. Lacy, J.E. Liljenquist, U. Keller, P.E. Williams, and A.D. Cherrington. 1980. Effect of glucose, independent of changes in insulin and glucagon secretion, on alanine metabolism in the conscious dog. J. Clin. Invest. 65:496-505.

29. Rodnick, K.J., W.L. Haskell, A.L.M. Swislocki, J.E. Foley, and G.M. Reaven. 1987. Improved insulin action in muscle, liver, and adipose tissue in physically trained human subjects. Am. J. Physiol. 253:E489-E495.

30. Mikines, K.J., B. Sonne, P.A. Farrell, B. Tronier, and H. Galbo. 1988. Effect of physical exercise on sensitivity and responsiveness to insulin in man. Am. J. Physiol. 254:E248-E259.

31. McMahon, M., W. Schwenk, M. Haymond, and R.A. Rizza. 1989. Underestimation of glucose turnover measured with [6-3H]- and [6,6 2H2]- but not [6-14C]glucose during hyperinsulinemia in human subjects. Diabetes. 38:97104.

32. Cersosimo, E., R.L. Judd, and J.M. Miles. 1994. Insulin regulation of renal glucose metabolism in conscious dogs. J. Clin. Invest. 93:2584-2589.

33. Stumvoll, M., U. Chintalapudi, G. Perriello, S. Welle, O. Gutierrez, and J.E. Gerich. 1995. Uptake and release of glucose by the human kidney. Postabsorptive rates and responses to epinephrine. J. Clin. Invest. 96:2528-2533.

34. Pagliassotti, M.J., S.R. Myers, M.C. Moore, D.W. Neal, and A.D. Cherrington. 1991. Magnitude of negative arterial-portal glucose gradient alters net hepatic glucose balance in conscious dogs. Diabetes. 40:1659-1668.

35. Mondon, C.E., C.B. Dolkas, and G.M. Reaven. 1980. Site of enhanced insulin sensitivity in exercise-trained rats at rest. Am. J. Physiol. 239:E169E177.

36. Holste, L.C., C.C. Connolly, and A.D. Cherrington. 1993. Glucagon can alter net hepatic glucose uptake during intraportal glucose delivery in the conscious dog. Diabetes. 42:243a. (Abstr.)

37. Wasserman, D.H. 1995. Control of glucose fluxes during exercise in the postabsorptive state. Ann. Rev. Physiol. 57:191-218

38. Garetto, L.P., E.A. Richter, M.N. Goodman, and N.B. Ruderman. 1984.
Enhanced muscle glucose metabolism after exercise in the rat: the two phases. Am. J. Physiol. 246:E471-E475.

39. Richter, E.A., L.P. Garetto, M.N. Goodman, and N.B. Ruderman. 1982 Muscle glucose metabolism following exercise in the rat. Increased sensitivity to insulin. J. Clin. Invest. 69:785-793.

40. Vergauwen, L., P. Hespel, and E.A. Richter. 1994. Adenosine receptors mediate synergistic stimulation of glucose uptake and transport by insulin and by contractions in rat skeletal muscle. J. Clin. Invest. 93:974-981.

41. Wasserman, D.H., R.J. Geer, D.E. Rice, D. Bracy, P.J. Flakoll, L.L Brown, J.O. Hill, and N.N. Abumrad. 1991. Interaction of exercise and insulin action in man. Am. J. Physiol. 260:E37-E45.

42. Richter, E.A., L.P. Garetto, M.N. Goodman, and N.B. Ruderman. 1984. Enhanced muscle glucose metabolism after exercise: modulation by local factors. Am. J. Physiol. 246:E476-E482.

43. Bogardus, C., P. Thuillez, E. Ravussin, B. Vasquez, M. Narimiga, and S. Azhar. 1983. Effect of muscle glycogen depletion on in vivo insulin action in man. J. Clin. Invest. 72:1605-1610.

44. Richter, E.A., K.J. Mikines, H. Galbo, and B. Kiens. 1989. Effect of exercise on insulin action in human skeletal muscle. J. Appl. Physiol. 66:876-885.

45. Ren, J.M., C.F. Semenkovich, E.A. Gulve, J.G. Gao, and J.O. Holloszy. 1994. Exercise induces rapid increases in GLUT4 expression, glucose transport capacity, and insulin-stimulated glycogen storage in muscle. J. Biol. Chem. 269: 14396-14401.

46. Koivisto, V.A., and H. Yki-Jarvinen. 1987. Effect of exercise on insulin binding and glucose transport in adipocytes of normal humans. J. Appl. Physiol. 63:1319-1323

47. Ahlborg, G., and P. Felig. 1976. Influence of glucose ingestion on fuelhormone response during prolonged exercise. J. Appl. Physiol. 41:683-688.

48. Ahlborg, G., and P. Felig. 1977. Substrate utilization during prolonged exercise preceded by ingestion of glucose. Am. J. Physiol. 233:E188-E194.

49. Felig, P., J. Wahren, and R. Hendler. 1975. Influence of oral glucose ingestion on splanchnic glucose and gluconeogenic substrate metabolism. Diabetes. 24:468-475.

50. Jackson, R.A., N. Peters, U. Advani, G. Perry, J. Rogers, W.H. Brough, and T.R.E. Pilkington. 1973. Forearm glucose uptake during oral glucose tolerance test in normal subjects. Diabetes. 22:442-458. 